\title{
Correction to: A randomised controlled trial of a mitochondrial therapeutic target for bipolar depression: mitochondrial agents, $\mathrm{N}$-acetylcysteine, and placebo
}

Michael Berk ${ }^{1,2,3,4^{*}}$, Alyna Turner ${ }^{1,2,5}$, Gin S. Malhi ${ }^{6,7,8}$, Chee H. Ng ${ }^{9}$, Susan M. Cotton ${ }^{4,10}$, Seetal Dodd ${ }^{1,2,10}$, Yuval Samuni ${ }^{1}$, Michelle Tanious ${ }^{6}$, Claire McAulay ${ }^{6}$, Nathan Dowling ${ }^{9}$, Jerome Sarris ${ }^{9,11}$, Lauren Owen ${ }^{12}$, Astrid Waterdrinker ${ }^{13}$, Deidre Smith ${ }^{9}$ and Olivia M. Dean ${ }^{1,2,3}$

\section{Correction to: BMC Med} https://doi.org/10.1186/s12916-019-1257-1

The original article [1] contained two minor errors:

1) Author, Chee H. Ng's middle initial was omitted;

2) The Competing Interests declaration omitted some information regarding author, Chee $\mathrm{H}$. Ng.

These two errors have since been corrected.

\section{Author details}

${ }^{1}$ IMPACT Strategic Research Centre, School of Medicine, Barwon Health, Deakin University, P.O. Box 291, Geelong, VIC, Australia. ²Department of Psychiatry, University of Melbourne, Royal Melbourne Hospital, Level 1 North, Main Block, Parkville, VIC, Australia. ${ }^{3}$ Florey Institute for Neuroscience and Mental Health, University of Melbourne, Kenneth Myer Building, 30 Royal Parade, Parkville, VIC, Australia. ${ }^{4}$ Orygen, The National Centre of Excellence in Youth Mental Health, 35 Poplar Rd, Parkville, VIC, Australia. ${ }^{5}$ School of Medicine and Public Health, Faculty of Health and Medicine, the University of Newcastle, Callaghan, NSW, Australia. ${ }^{6}$ CADE Clinic, Royal North Shore Hospital, Northern Sydney Local Health District, St Leonards, NSW, Australia. ${ }^{7}$ Academic Department of Psychiatry, Kolling Institute, Northern Sydney Local Health District, St Leonards, NSW, Australia. ${ }^{8}$ ARCHI, Sydney Medical School Northern, University of Sydney, Sydney, NSW, Australia. ${ }^{9}$ Department of Psychiatry, University of Melbourne, the Melbourne Clinic, 130 Church St Richmond, Melbourne, VIC, Australia. ${ }^{10}$ Centre for Youth Mental Health, The University of Melbourne, 35 Poplar Rd, Parkville, VIC, Australia. ${ }^{11} \mathrm{NICM}$, School of Health and Science, Western Sydney University, Campbelltown, NSW, Australia. ${ }^{12}$ School of Psychology, University of Central Lancashire, Preston, UK. ${ }^{13}$ Melbourne Health, 300 Grattan St, Melbourne, VIC, Australia.
Received: 4 February 2019 Accepted: 4 February 2019

Published online: 17 February 2019

\section{Reference}

1. Berk $\mathrm{M}$, et al. A randomised controlled trial of a mitochondrial therapeutic target for bipolar depression: mitochondrial agents, N-acetylcysteine, and placebo. BMC Med. 2019;17:18 https://doi.org/10.1186/s12916-019-1257-1.

* Correspondence: mikebe@barwonhealth.org.au

'IMPACT Strategic Research Centre, School of Medicine, Barwon Health, Deakin University, P.O. Box 291, Geelong, VIC, Australia

${ }^{2}$ Department of Psychiatry, University of Melbourne, Royal Melbourne

Hospital, Level 1 North, Main Block, Parkville, VIC, Australia

Full list of author information is available at the end of the article

(c) The Author(s). 2019 Open Access This article is distributed under the terms of the Creative Commons Attribution 4.0 International License (http://creativecommons.org/licenses/by/4.0/), which permits unrestricted use, distribution, and reproduction in any medium, provided you give appropriate credit to the original author(s) and the source, provide a link to the Creative Commons license, and indicate if changes were made. The Creative Commons Public Domain Dedication waiver (http://creativecommons.org/publicdomain/zero/1.0/) applies to the data made available in this article, unless otherwise stated. 